\title{
MENELUSURI MANUSIA SUPER DARI KESUSASTRAAN TRADISIONAL
}

\section{Eka Meigalia}

\begin{abstract}
Abstact
This research describes superhero in the traditional literature. In Minangkabau traditional literature such as kaba, there are main characters Cindua Mato, Anggun Nan Tongga, and Rambun Pamenan. But they are not familiar, especially for the young generation. This is happen because there are no other type from kaba which is easy to understand by the young generation.
\end{abstract}

Keywords: kaba, superhero, traditional literature.

\section{Pendahuluan}

Jika berbicara tokoh manusia super atau "superhero", bisa jadi yang muncul dalam pikiran kita adalah nama-nama seperti Batman, Superman, Robinhood, Satria Baja Hitam, atau yang lainnya. Namun bisa juga yang terlintas adalah nama-nama tokoh hebat dari Indonesia sendiri seperti Gatot Kaca dan Si Pitung. Nama-nama tersebut dikaitkan dengan istilah "manusia super" karena kekuatan dan kehebatannya dalam memberantas kejahatan. Juga karena kelebihan-kelebihan yang mereka miliki yang berbeda dengan manusia biasa. Ada yang bisa terbang, ada yang tahan benda-benda tajam, dan juga mampu mengangkat benda-benda yang sangat berat.

Beberapa tokoh superhero tersebut, baik dari luar atau pun dari dalam negeri, berasal dari cerita-cerita tradisional atau kesusastraan tradisional satu kelompok masyarakat. Misalnya saja tokoh Gatot Kaca yang berasal dari kesusastraan tradisional Jawa. Gatot Kaca adalah tokoh dalam kisah Mahabarata di Jawa yang terkenal sebagai kesatria perkasa, berotot kawat dan bertulang besi.

Jika di Jawa ada kesusastraan tradisionalnya yang biasa disebut kakawin, Minangkabau juga memilikinya, yaitu kaba. Menurut Djamaris (2002:77), kaba adalah cerita prosa berirama, berbentuk narasi (kisahan), dan tergolong cerita 
panjang. Kaba ini awalnya disampaikan secara lisan dengan didendangkan atau dilagukan dengan iringan alat musik tradisional. Kemudian kaba ini mulai dituliskan dalam manuskrip-manuskrip hingga sekarang telah pula dicetak untuk dapat dibaca oleh masyarakat umum.

Cerita-cerita yang ada dalam kaba ini sebenarnya sangat beragam. Ada yang tergolong pada cerita penglipur lara, yaitu yang pada awalnya sedih, penuh penderitaan, namun berakhir dengan kebahagiaan. Ada juga yang menampilkan kehebatan dan perjuangan seorang tokoh yang menurut Djamaris (2002:78) termasuk epos (cerita kepahlawanan) seperti Cindua Mato dan Anggun nan Tungga. Akan tetapi, apakah kita telah mengenali tokoh-tokoh "superhero" atau manusia super yang ada dalam kaba tersebut? Apakah dalam menjawab pertanyaan tokoh "superhero" favorit kita, kita akan menyebutkan tokoh-tokoh yang ada dalam kaba tersebut?

Berdasarkan pemikiran tersebut, melalui tulisan ini penulis mengulas beberapa tokoh yang ada dalam kaba yang bisa disebut sebagai "manusia super" dari Minangkabau. Selain itu, penulis juga mengulas hal-hal apa saja yang membuat tokoh-tokoh tersebut tidak terkenal seperti Gatot Kaca atau Si Pitung dan dalam kerangka konsep ekonomi kreatif, hal-hal apa saja yang bisa dilakukan agar tokohtokoh itu dapat dikenal juga dalam skala nasional maupun internasional.

Untuk itu, ulasan yang penulis lakukan ini dilakukan dengan menggunakan metode kualitatif yang menitikberatkan pekerjaan pada interpretasi dan tafsiran terhadap data dan objek penelitian. Proses pemerolehan data dilakukan dengan studi kepustakaan, yaitu dengan memetakan kaba di Minangkabau untuk kemudian memilih kaba dengan tokoh utamanya secara umum memiliki karakteristik sebagai manusia super. Kemudian dilakukan analisis terhadap tokoh utama dari kaba-kaba tersebut yang mencakup tokoh dan penokohan serta alur cerita atau peristiwaperistiwa dalam cerita yang mendukung terbentuknya karakter sebagai manusia super dari tokoh tersebut.

\section{Manusia Super dalam Kaba}

Tokoh "superhero" atau manusia super dalam hal ini dibatasi pada istilah yang merujuk pada tokoh manusia yang ada dalam kaba, yang memiliki kelebihan dibandingkan dengan manusia biasa, luar biasa, dan istimewa. Ada pun tokoh manusia super ini biasanya ditemukan dalam kaba lama atau kaba klasik. Junus (1984:19) menjelaskan ciri-ciri kaba lama tersebut sebagai berikut.

1. Ceritanya mengenai perebutan kekuasaan antara dua kelompok 
2. Ceritanya dianggap berlaku pada waktu lampau yang jauh, dan tentang anak raja dengan kekuatan supernatural.

Karena tokoh yang ada dalam kaba tersebut biasanya memiliki kekuatan supernatural, tokoh tersebut bisa dikatakan memiliki kelebihan dibandingkan dengan manusia biasa.

Berdasarkan penelusuran penulis, ada beberapa tokoh dalam kaba klasik ini yang kekuatannya bisa dikatakan menakjubkan. Tokoh pertama adalah Cindua Mato dalam kaba Cindua Mato. Kaba ini sendiri menurut Djamaris (2002:79) termasuk pada sastra pahlawan, sastra epos, atau wira cerita, yaitu cerita yang mengisahkan perjuangan seorang tokoh untuk mencapai tujuan yang terpuji. Dalam kaba Cindua Mato, kisah kepahlawanannya terlihat pada perjuangan Cindua Mato membela keluarganya di Negeri Pagaruyuang.

Sosok Cindua Mato sendiri dapat dikatakan istimewa atau memiliki kelebihan dibandingkan manusia biasa dalam beberapa hal. Dari kelahirannya, Cindua Mato sudah dikatakan sebagai urang keramat, orang bertuah. Berikut kutipan yang menunjukkan keramat dan bertuahnya Cindua Mato.

Diliek anak laki-laki, laki-laki kaduonyo, tibo di lantai lantai tabuah, tibo di tanah tanah lambang, anak babaju kaduonyo, anak batuah jo kiramaik, tidak dapek ditantang nyato, bak mamandang matohari, satu ado satu banamo. Surang banamo Sutan Rumanduang, anak Rajo kito, Mangkuto Ulak Tanjuang Bungi, tinggi nan tidak bapucuak, mamacik tampuak Minangkabau. Nan surang banamo Cindua Mato, urang kiramaik kaduonyo, urang batuah hiduik-hiduik, kalau ditantang mato buto, kalo disabuk lidah kalu, kalau dikana hati litak, ruponyo rancak kaduonyo, bak pinang dibalah duo, sarupo dasun dibalah ampek, ragulah urang mamandangi. (hlm.11)

(Dilihat anak laki-laki, laki-laki keduanya, tiba di lantai lantai babunyi, tibo di tanah tanah lembang, anak berbaju keduanya, anak bertuah dan keramat, tidak dapat ditantang, seperti memandang matahari, satu ada satu bernama. Seorang bernama Sutan Rumanduang, anak Raja kita, Mangkuto Ulak Tanjuan Bungi, tinggi yang tidak berpucuk, memegang tampuk Minangkabau, Yang satu bernama Cindua Mato, orang keramat keduanya, orang bertuah hidup-hidup, kalau ditantang mata buta, kalau disebut lidah kelu, kalau diingat hati letih, rupa bagus keduanya, seperti pinang dibelah dua, seperti dasun dibelah empat, ragulah orang memandangi.)

Dari kutipan di atas terlihat bahwa saat lahir Cindua Mato lahir 
bersamaan dengan anak Bundo Kanduang, Sutan Rumanduang. Saat lahir, "tibo di lantai lantai tabuah, tibo di tanah tanah lambang". Hal itu menggambarkan keanehan yang terjadi ketika lahirnya Cindua Mato dan Sutan Rumanduang. Selain itu pada kutipan tersebut kekeramatan Cindua Mato digambarkan begitu hebatnya sehingga tidak bisa ditantang secara langsung karena bisa buta, kalau disebut lidah akan kelu, dan kalau diingat, hati tak akan sanggup mengingatnya.

Kelebihan dan kehebatan Cindua Mato juga terlihat ketika melewati Bukit Tambun Tulang yang dihuni oleh banyak penyamun saat menuju Nagari Silakawi. Di bukit itu begitu banyaknya tulang orang mati yang bertumpuk-tumpuk hingga sudah seperti menggunung. Cindua Mato sendiri ternyata mampu membuat tengkorak orang yang mati itu bisa berbicara untuk menceritakan penyebab kematiannya. Berikut kutipan yang memperlihatkan kehabatan Cindua Mato tersebut.

Lalu dikunyah siriah sakapua, siriah banamo tanyo-tanyo, disambua tangkurak nan banyak: "Mano tuan urang mati, apo sabab karanonyo, mako tuan mati di siko."

Ado sabanta antaranyo, dek sati siriah tanyo-tanyo, bakato tangkurak nan tun: "Ampun hambo Tuan Kaciak, lorong kapado badan kami, mati dibunuah urang panyamun, panyamun banyak baribu-ribu.... (hlm. 37)

(Lalu dikunyak sekapur sirih, sirih bernama "tanyo-tanyo", disembur tengkorak yang banyak," Wahai tuan orang mati, apa sebab karenanya tuan mati di sini."

Sebentar kemudian, karena saktinya sirih "tanya-tanya", berkata tengkorak itu: "Ampun hamba Tuan Kaciak, yang terjadi pada diri kami, mati dibunuh orang penyamun, penyamun banyak beriburibu...)

Dari kutipan di atas terlihat bahwa Cindua Mato mengunyah sirih yang disebut "tanyo-tanyo" untuk membuat tengkorak yang banyak itu berbicara. Sirih yang sudah dikunyak itu kemudian disemburkan kepada tongkorak hingga tengkorak itu bisa menceritakan penyebab kematiannya. Tengkorak itu menceritakan bahwa penyamun lah yang membunuh mereka dan penyamun itu jumlahnya beribu-ribu. Tengkorak itu juga menceritakan penyamun seperti apa yang nanti akan dihadapi Cindua Mato. Berikut kutipannya.

Kalau nan manjadi kapalonyo, banamo Datuak Maruntun Manau, badan gapuak tinggi gadang, lompeknyo sakayu kain. Surang banamo Datuak 
Biawak, badannyo kasek arang busuak mato tabudua gigi tanggiang, badan hitam bak amparo, tahan gurindam tahan gargaji, suaro sebagai mambalah batuang. Nan surang Datuak Salah Cangkuang, tinggi duduak pado tagak muko capuak mato celek, bulu dado sarupo ijuak, sisunguik marantiang batuang, pandai mamanjek sarupo tupai. Nan surang Datuak Palajang Bukik, padang salaweh daun pisang, kaki capek tangan capek, nan manggauik jo kukuran nan mamakan ampiang basi, suaro gagok bibia taleo, gigi hitam gadang-gadang, baun busuak katiak amih, paruik buncik makannyo banyak. (hlm37-38)

(Kalau yang menajadi pimpinannya bernama Datuang Maruntun Manau, badan gemuk tinggi besar, lompatannya sangat panjang. Seorang bernama Datuak Biawak, badannya kesat mulut berbau mata melotot gigi tonggos, badan hitam seperti sisa bara, tahan benda tajam, suara seperti membelah bambu. Yang satu Datuak Salah Cangkuang, tinggi duduk dari pada berdiri muka bopeng mata kotor, bulu dada seperti ijuk, janggut seperti ranting bambu, pandai memanjat seperti tupai. Yang seorang Datuak Palajang Bukik, pedang sebesar daun pisang, kaki cepat tangan cepat, yang menggaruk setajam kukuran yang memakan emping besi, suara gagap bibir dower, gigi hitam besar-besar, bau busuk ketiak amis, perut buncit makannya banyak.)

Para penyamun yang digambarkan dalam kutipan di atas memiliki kelebihan dibandingkan dengan manusia biasa, seperti Datuak Maruntun Manau yang lompatannya panjang, Datuak Biawak yang kebal dari bendabenda tajam, Datuak Salah Cangkuang pandai memanjat, dan Datuak Palajang Bukik yang garukan kukunya sangat tajam. Selain itu, para penyamun itu rupanya juga sangat buruk dan menyeramkan. Ada yang gemuk tinggi besar, ada yang janggutnya sangat kasar, muka bopeng, mata besar, kulit kasar, dan sebagainya.

Jika dibayangkan, gambaran mengenai penyamun tersebut akan membuat takut siapa saja. Jangankan melawan mereka, bertemu pun rasanya sudah sangat menakutkan. Ternyata Cindua Mato pun merasakan ketakutan itu. Hatinya tidak tenang juga. Akan tetapi di sini kembali terlihat kehebatannya dalam mengendalikan ketakutan tersebut. Berikut kutipannya.

Kan iyo Cindua Mato, inyo babaliak ateh kudo, kudo diracak hanyo lai, si Binuang manuruik di balakang. Badan nan angek-angek dingin, hati nan indak sanang lai, ilimu firasaik mambisiakkan, tibo di ranah babahayo.

Ado sabanta antaronyo, tampak tanah lambang-lambang, lah banyak rumpuik nan layua, busuak nan indak tabadokan, paniang kapalo mambauni. Tadanga urang mahimbau-himbau, tadanya bunyi pakiak 
urang, tadanga di dalam rimbo gadang, garik ganta lah taraso, maramang kuduak katakutan.

Takana doa Bundo Kanduang, doa piganta jo pidareh, cukuik jo doa sikalumun, hilang sajo dipandang dipandang urang, dibaco doa barani tibo, indak takuik jo siapo. Sasudah ilimu diamakan, kan iyo samaso itu, timbua bagak jo barani, hilang takuik jo ganta... (hlm.38)

(Cindua Mato pada masa itu pun kembali ke atas kuda, kuda pun ditunggangi, Si Binuang mengikuti dari belakang. Badang yang panas-panas dingin, hati yang tidak senang lagi, ilmu firasat membisikkan bahwa telah tiba di wilayah berbahaya.

Ada sebentar antaranya, tampak tanah landai, sudah banyak rumput yang layu, busuk yang tiada tara, pusing kepala membauinya. Terdengar orang memanggil-manggil, terdengar bunyi pekik prang, terdengar di dalam rimba raya, sehingga perasaan gentar mulai timbul, merinding tengkuk ketakutan.)

Kutipan di atas menunjukkan bahwa Cindua Mato memiliki doa "piganta jo pidareh" juga doa "sikalumun" yang didapatkan dari Bundo Kanduang. Doa tersebut dapat menghilangkan segala rasa cemas dan takut dalam dirinya. Dan memang, berdasarkan kutipan di atas dapat dilihat bahwa segala rasa takut dan gentarnya hilang, berganti rasa berani. Seandainya Cindua Mato tidak memiliki kelebihan tersebut, belum tentu Cindua Mato akan meneruskan perjalanannya mengingat segala bahaya yang menghadangnya.

Selain kelebihan-kelebihan dari Cindua Mato yang telah dijelaskan di atas, Cindua Mato dalam kaba juga dikisahkan sebagai orang yang cerdik. Hal itu salah satunya diperlihatkan ketika Cindua Mato harus berhadapan dengan Rajo Tiang Bungkuak. Rajo Tiang Bungkuak ini ayah dari Imbang Jayo yang sebelumnya terbunuh dalam peperangan dengan pihak Istana Pagaruyuang. Rajo Tiang Bungkuak ini pun terkenal sebagai orang kuat yang tahan besi, tidak ada satu senjata pun yang mampu melukainya.

Dalam pertempuran awal dengan Rajo Imbang Jayo, Cindua Mato kalah. Karena kekalahannya itu, Cindua Mato terpaksa menjadi budak Imbang Jayo. Setiap hari pekerjaannya melayani Rajo Imbang Jayo. Sedangkan makan yang diberikan kepada Cindua Mato hanya kerak nasi yang juga sudah basah.

Akan tetapi ternyata Cindua Mato tidak diam dan pasrah saja dengan keadaan itu. Cindua Mato diam-diam memikirkan dan mengatur cara untuk mencari kelemahan Rajo Tiang Bungkuak. Maka kesempatan untuk mencari kelemahan Rajo Tiang Bungkuak didapatnya saat Raja 
itu tidur. Dengan menggunakan siriah tanyo-tanyo, Cindua Mato berhasil mendapatkan informasi mengenai kelemahan Rajo Tiang Bungkuak seperti terungkap dalam kutipan berikut.

Kan iyo samaso itu, hari nan sadang tangah hari, sadang bunta bayingbayang, diuruik kaki Tiang Bungkuak, sadang lalok babariang-bariang, talalok mato Tiang Bungkuak, bunyi karuah bak aia tajun. Sadang talalok sangaik lamak, dikunyah siriah nan sakapua, siriah banamo tanyo-tanyo, ditanyo kapado Tiang Bungkuak;

"Manolah Rajo Tiang Bungkuak, di mano angok dilatakkan, tarangkan bana jaleh-jaleh".

Tiang Bungkuak tidak manyauik, maliek rupo nan bak kian, inyo manyambua sakali lai, kanai ubun-ubun Tiang Bungkuak, lalu batanyo Cindua Mato,"Manolah Rajo Tiang Bungkuak, apo sababnyo sakaba itu, ilimu apo nan dipakai, jo apo pambunuah mako mati."

Barakaik sati siriah tanyo-tanyo, sanan bakato Tiang Bungkuak, "Manolah waang Cindua Mato, kalau itu nan ang tanyokan, jikok handak mambunuah hambo, jo karih bungkuak nan hambo punyo, talatak di ateh tunggak bungkuak," katonyo Rajo Tiang Bungkuak. (hlm. 106)

(Maka semasa itu, hari yang sedang tengah hari, sedang bunta baying-bayang, diurut kaki Tiang Bungkuak, sedang tidur berbaring, terlelap mata Tiang Bungkuak, bunyi dengkur seperti air terjun. Sedang tidur sangat nyenyak, dikunyah sirih yang sekapur, sirih bernama tanyo-tanyo, ditanya kepada Tiang Bungkuak;

"Wahai Raja Tiang Bungkuak, di mana nyawa diletakkan, terangkan jelas-jelas."

Tiang Bungkuak tidak menyahut, melihat rupa yang seperti itu, dia menyembur sekali lagi, kena ubun-ubun Tiang Bungkuak, lalu bertanya Cindua Mato, "Wahai Rajo Tlang Bungkuak, apa sebabnya sekebal itu, ilmu apa yang dipakai, dengan apa bisa dibunuh hingga mati."

Berkat sakti sirih tanyo-tanyo, maka berkata Tiang Bungkuak, "Wahai Cindua Mato, kalau itu yang kau tanyakan, jika hendak membunuhku, dengan keris bungkuk yang aku punya, terletak di atas tonggak bungkuk," katonyo Rajo Tiang Bungkuak.)

Maka setelah berhasil mendapatkan informasi mengenai kelemahan Rajo Tiang Bungkuak, Cindua Mato pun kemudian berhasil mengalahkan Rajo Tiang Bungkuak. Kutipan di atas memperlihatkan bahwa selain memiliki kesaktian dan benda-benda sakti seperti siriah tanyo-tanyo, Cindua Mato pun adalah orang yang juga cerdas dan tidak menghandalkan kesaktian benda-benda yang dimilikinya saja untuk mengalahkan musuh.

Berdasarkan paparan di atas, dapat dilihat bahwa Cindua Mato 
adalah tokoh dalam kaba yang memiliki keistimewaan, yang berbeda dengan manusia biasa. Selain Cindua Mato, tokoh lainnya dalam kaba klasik Minangkabau yang juga dapat dikatakan memiliki keistimewaan dan berbeda dengan manusia biasa adalah Anggun Nan Tongga.

Anggun Nan Tongga adalah anak dari Ganto Pamai. Kelahiran Anggun Nan Tongga ini juga hampir sama dengan Cindua Mato. Saat ia lahir, sudah terlihat kelebihan dan perbedaannya dengan manusia pada umumnya. Hal itu diungkapkan dalam kutipan berikut.

Dek Allah sadang manggarakkan, tibo di lantai lantai putuih, tibo dirusuak rusuak taban, tibo di tanah tanah lambang, anak lahia jo karuangnyo.

Badantuang patuih maso itu, babuni gaga di lawuitan, babuai guruah dari hulu, bakukuak ayam nan kinantan, babuni balam tigo gayo, maringgih kudo sambarani, manyentak karih nan pusako, raso ka luluih rumah gadang sambilan ruang, panjang nan tidak panjang bana, salajang kudo balari, sakuaik kuaran tabang. (hlm.12)

(Karena Allah sedang menggerakkan, tiba di lantai lantai putus, tiba di rusuk rusuk taban, tiba di tanah tanah lembang, anak lahir dengan karungnya.

Berdentum petir masa itu, berbuni gaga di lautan, berbuih guruh dari hulu, berkukuk ayam kinantan, berbunyi balam tigo gayo, meringkik kuda sembrani, menyentak keris pusaka, seolah akan luluh rumah gadang sembilan ruang, panjang yang tidak panjang sekali, selajang kuda berlari, sekuat kuaran terbang.)

Pada kutipan tersebut digambarkan bahwa saat Anggun Nan Tongga lahir, alam pun seolah turut menyambutnya. Berbagai bunyian terdengar, seperti petir, ayam, balam, kuda, dan lannya. Belum lagi Nan Tongga dikisahkan lahir dengan karungnya. Artinya dia lahir tidak seperti manusia biasa.

Di samping itu, karung yang membungkus Nan Tongga saat lahir juga diceritakan tidak mudah untuk dirobek. Hal itu disampaikan dalam kutipan berikut.

Urang lah heboh dalam nagari, panuah jorong Kampuang Dalam, sadang dek si Kambang Alamsari sugiro diambiak budak nantun, lalu dibaok ka ateh rumah, anak di dalam karuang kulik, diambiak pisau dalam peti, pisau sirauik basi baiak, lalu dituriah karuang nantun, usahkan karuang kan cabiak, hanyo pisau nan sumbiangsumbiang.

Diambiak pulo karih sabilah, diantak pulo karuang nantun, usah 
kan karuang ka tabuak, karih habih baliuak-liuak, hilanglah aka maso itu, budak di dalam karuang juo... (hlm.12)

(Orang sudah heboh dalam negeri, penuh jorong Kampuang Dalam, sedangkan oleh si Kambang Alamsari segera diambil anak itu, lalu dibawa ke atas rumah, anak di dalam karung kulit, diambil pisau dalam peti, pisau sirauik besi yang bagus, lalu ditoreh karung itu, jangankan karung yang robek, hanya pisau yang sumbingsumbing.

Diambil pula keris sebilah, ditusuk pula karung itu, jangankan karung kan tembus, keris habis bengkok-bengkok, hilanglah akal masa itu, anak di dalam karung juga.)

Kutipan di atas memperlihatkan betapa berbedanya kelahiran Anggun Nan Tongga dengan manusia biasa. Apalagi karung yang dimaksud dalam cerita disebutkan adalah "karung kulit" yang tidak bisa dirobek dan dirusak oleh benda tajam apa pun. Ternyata dikisahkan lagi bahwa benda tajam yang bisa merobek karung kulit itu adalah rencong Aceh, rencong pusaka. Maka setelah karung kulit itu dirobek dengan rencong Aceh itu, barulah wujud Anggun Nan Tungga dapat dilihat. Dia diberi gelar Magek Durahman yang jelas-jelas dalam cerita disebutkan sebagai orang keramat seperti dalam kutipan berikut.

...lalu dituriahnyo karuang nantun, kalualah anak laki-laki, itulah Anggun Nan Tongga Magek Jabang, nan bagala Magek Durahman, urang surang banamo tigo, anak rang kiramaik hiduik-hiduik. (hlm.13)

...kemudian ditorehnya karung itu, keluarlah anak laki-laki, itulah Anggun Nan Tongga Magek Jobang, nan bagala Magek Durahman, orang seorang bernama tiga, anak orang keramat hidup-hidup.

Dengan proses kelahirannya yang luar biasa itu, setelah dewasa pun Anggun Nan Tongga benar-benar menjadi manusia yang luar biasa. Dia menjadi pemuda yang pemberani dan tidak takut dengan apa pun. Keberanian Nan Tongga ini salah satunya terlihat ketika dia menyatakan akan pergi mengarungi lautan mencari tiga orang mamaknya yang memang telah lama hilang saat berlayar. Bagi Nan Tongga, adalah satu hal yang memalukan jika dia hanya berdiam dan bermain di gelanggang saja sementara tiga orang mamaknya telah hilang tidak tahu rimbanya. Untuk itu lah dia membulatkan tekat untuk berlayar mencari mamaknya meskipun dia tahu bahwa perjalanan yang akan ditempuhnya tidak akan 
mudah. Begitu banyak ancaman dan marabahaya yang akan menimpanya nanti. Akan tetapi, karena keberanian yang dimilikinya itulah Nan Tongga tetap melakukan perjalanan itu.

Dalam perjalanan itu memang terjadi berbagai permasalah yang kembali menguji keberanian dan juga kehebatan Nan Tongga. Di antaranya adalah para bajak laut yang menjaga Pulau Binuang Sati. Ketika kapal Nan Tongga hampir sampai di pulau tersebut, para awak kapal pun sudah ketakutan dan memperingatkan Nan Tongga betapa berbahayanya pulau tersebut. Banyak kapal yang tidak selamat dan banyak orang yang mati pula setelah masuk ke pulau itu. Meskipun telah diperingatkan seperti itu, Nan Tongga tidak takut dan tetap melanjutkan perjalanannya menuju pulau tersebut karena dia yakin salah seorang mamaknya ada di pulau itu. Keberanian Nan Tongga tersebut diperlihatkan dalam kutipan berikut.

Manjawab sanan tuan Tongga,"Manolah manti nan piawai, limbak nan Dandang Panjang nangko, bapantang karam dilawitan, malangnyo lapuak di kalangan, ka hilia mancari lawan, ka mudiak mancari musuah, sajak salangkah dari kampuang, sajak satapak dari rumah, handak manjalang pulau nangko, iyo pulau Binuang Sati, handak batamu Palimo Bajau, nan dicubo masin garamnyo, handak diraso padeh ladonyo, katokan baitu pasan kami, kami nan tidak ka barangkek!" (hlm.74)

(Menjawablah tuan Tongga, "Wahai manti yang piawai, di pihak Dandang Panjang ini, berpantang karam di lautan, malanya lapuk di kalangan, ke hilir mencari lawan, ke mudik mencari musuh, sejak selangkah dari kampong, sejak setapak dari rumah, hendak menjelang pulau ini, yaitu pulau Binuang Sati, hendak bertemu Palimo Bajau, yang akan dicoba asin garamnya, hendak dirasa pedas cabenya, katakan begitu kami, kami yang tidak akan pergi.)

Kutipan di atas adalah kutipan dari bagian saat Nan Tongga menjawab ancaman dari para bajak laut agar ia segera meninggalkan pulau. Akan tetapi karena keberaniannya dan juga bulatnya tekat Nan Tongga untuk mencari mamaknya, dia tidak mundur atau pun gentar. Karena kekerasan hati Nan Tongga untuk masuk ke pulau itu pula yang membuat para bajak laut yang menghuni pulau itu akhirnya mendatanginya. Kepala para bajak laut yang bernama Palimo Bajau sendiri yang memimpin pasukannya untuk menyerang kapal Anggun Nan Tongga.

Maka peperangan pun terjadi di lautan. Antara kapal Nan Tongga dengan kapal para bajak laut saling melempar tembakan. Ketika kedua kapal mendekat, pertempuran antara para bajak laut dan awak kapal Nan 
Tongga pun terjadi. Nan Tongga sendiri akhirnya berhadapan langsung dengan Palimo Bajau. Palimo Bajau sendiri akhirnya berhasil dikalahkan dalam pertarungan itu sehingga dia mati.

Karena pimpinannya sudah mati, para bajak laut lainnya akhirnya menyerahkan diri. Tujuan Anggun Nan Tongga untuk masuk ke pulau Binuang Sati untuk mencari mamaknya pun terwujud. Dia berhasil bertemu dengan salah satu mamaknya, yaitu Nangkodoh Rajo, yang memang selama ini menjadi tawanan para bajak laut di sana.

Setelah berhasil bertemu dengan salah satu mamaknya, Nan Tongga kembali melanjutkan pelayarannya untuk mencari mamaknya yang dua orang lagi. Dengan tidak begitu banyak halangan dan masalah yang datang, Nan Tongga berhasil menemukan kedua mamaknya. Ternyata saat menuju Pulau Binuang Sati, tiga orang mamak Anggun Nan Tongga dihadang bajak laut. Satu orang mamaknya, yaitu Nangkodoh Rajo berhasil ditangkap dan ditawan bajak laut, sedangkan yang berdua berhasil melarikan diri. Akhirnya misi Anggun Nan Tongga untuk mencari mamaknya yang hilang dilautan berhasil ia selesaikan karena keberaniannya.

Kemudian tokoh yang juga digambarkan memiliki keberanian dan berbeda dengan manusia biasa dalam kesuastraan tradisional masyarakat Minangkabau ini adalah Rambun Pamenan. Tokoh Rambun Pamenan ini terdapat dalam kaba yang berjudul "Rambun Pamenan". Dalam kaba ini Rambun Pamenan dikisahkan pergi mencari Ibunya yang dilarikan oleh Rajo Angek Garang ke Nagari Camin Taruih yang sangat jauh bahkan tidak jelas di mana tempatnya. Perjalanan menuju Camin Taruih ini tidaklah mudah. Banyak sekali marabahaya dan rintangan yang menghadang. Ia harus melewati rimba yang besar yang dihuni oleh berbagai binatang buas. Belum lagi jika sampai di Camin Taruih, Rambun Pamenan harus berhadapan dengan Rajo Angek Garang beserta anak buahnya yang terkenal kejam untuk membebaskan Ibunya. Berbagai rintangan dan marabahaya ini tidak menghalangi Rambun Pamenan untuk mencari Ibunya.

Selain keberanian Rambun Pamenan ini, di sini juga diceritakan juga bahwa dalam perjalanannya, Rambun Pamenan bertemu dan ditolong oleh beberapa binatang yang tidak biasa kita temui dalam kehidupan seharihari. Bahkan binatang yang muncul dalam kisah ini juga ada yang bisa berdialog dengan manusia.

Tokoh binatang itu yang pertama adalah buruang Borak. Burung ini merupakan burung milik Rajo Angek Garang, tokoh antagonis dalam cerita 
ini. Burung ini pun diceritakan dapat berbicara dengan Rajo Angek Garang. Berikut kutipan yang memperlihatkan percakapan di antara keduanya.

\section{"Ambo lah mandapek kaba, bahaso suaminyo alah mati," buruang Borak mangatokan.}

Bulek pikiran samaso itu, mukasuik ka maambiak Linduang Bulan, supayo nak sanang paratian, sanan bakato Rajo Angek Garang, kapado buruang Borak nantun," Adiak kanduang Si Buruang Borak, kito bajalan kini-kini, manjapuik Puti Linduang Bulan, ka ranah ka Kampuang Dalam, suko tak suko inyo pai, namun inyo dibaok juo."

Manjawab Si Buruang Borak,"Kalau baitu kato Angku, kito bajalan kini juo, samantaro hari balun tinggi." (hlm.11-12)

"Saya sudah mendapat kabar bahwa suaminya sudah mati," kata burung Borak.

Bulat pikiran waktu itu, maksud akan mengambil Linduang Bulan, agar hati senang, berkata Rajo Angek Garang, kepada burung Borak itu," Adik kandung si Burung Borak, kita berjalan sekarang, menjemput Puti Linduang Bulan, ke ranah, ke Kampung dalam, suka tak suka dia pergi, namun dia dibawa juga."

Menjawab si Burung Borak,"Kalau begitu kata Angku, kita berjalan sekarang juga, sementara hari belum terlalu siang."

Selain itu, tokoh binatang lainnya adalah Si Alang Bangkeh. Dalam cerita ini memang tidak ada percakapan yang terjadi antara si elang dengan manusia. Tetapi burung ini mengerti dengan permintaan yang diajukan oleh Puti Linduang Bulan. Puti Linduang Bulan meminta pada burung ini untuk mengantarkan surat kepada anaknya Puti Rono Pinang dan Rambun Pamenan. Burung inilah yang mengantarkan pesan kepada Rambun Pamenan mengenai keadaan Puti Linduang Bulan yang tak lain adalah ibunya.

Berikutnya ada lagi seekor burung yang juga menjadi penolong dalam cerita ini, yaitu balam timbago. Balam timbago ini merupakan perantara antara Puti Rono Pinang dengan Rambun Pamenan ketika Rambun Pamenan melakukan perjalanan untuk menyelamatkan ibunya. Balam timbago di sini juga bisa bercakap-cakap dengan manusia. Berikut kutipannya.

....tidak ado urang nan tampak, salain dari balam timbago, manangih Rambun Pamenan,"Adiak kanduang badan diri, apo sabab datang ka mari, jo sia aciak ditinggakan, hilang surang hilang baduo, kini baitu malah di adiak, babaliak pulang malah adiak."

Manjawab Balam Timbago,"Tuan kaciak janyo ambo, makanlah nasi nan sakapa, sarato talua nan sabuah, nak kuaik Tuan bajalan, kok sampai tamakan habih, tigo tahun tahinda lapa." (hlm.41) 
.... tidak ada orang yang tampak, selain dari balam timbago, menangis Rambun Pamenan, "Adik kandung di badan diri, apa sebab datang ke mari, dengan siapa Aciak ditinggalkan, hilang seorang hilang berdua, sekarang baiknya bagi adik, berbalik pulanglah adik.

Menjawab Balam Timbago,"Tuan Kaciak dengarkan saya, makanlah nasi yang sekepal, serta telur yang sebuah, agar kuat tuan berjalan, jika termakan habis, tiga tahun terhindar dari lapar.

Burung yang juga menjadi penolong Rambun Pamenan selanjutnya adalah burung Garuda. Burung inijuga berdialog dengan Rambun Pamenan. Kemunculan tokoh-tokoh binatang yang tidak biasa ini justru membuat tokoh Rambun Pamenan menjadi tokoh yang tidak seperti manusia biasa. Selain keberaniannya, begitu banyak kemujuran yang diperolehnya sebagai seorang manusia sehingga setiap kali ditimpa masalah, dia berhasil melewatinya.

\section{Ketersohoran Tokoh Superhero dari Kaba}

Berdasarkan ulasan di atas ditemukan tiga tokoh dari kaba Minangkabau yang dapat dikategorikan sebagai manusia super, yaitu manusia yang memiliki kelebihan dibandingkan dengan manusia pada umumnya. Tokoh tersebut adalah Cindua Mato, Anggun Nan Tongga, serta Rambun Pamenan. Namun tidak tertutup kemungkinan masih ada lagi tokoh-tokoh dalam kaba yang dapat dikategorikan sebagai manusia super.

Berbeda dengan Gatot Kaca, Si Pitung, atau tokoh superhero Indonesia lainnya yang berasal dari kesusastraan tradisional, Cindua Mato, Anggun Nan Tongga, maupun Rambun Pamenan tidak terkenal. Bahkan di kalangan masyarakat Minangkabau sendiri tokoh-tokoh tersebut tidak dikenali, terutama generasi muda. Anak-anak di Minangkabau lebih kenal dengan Superman, Batman, Spiderman, dan tokoh-tokoh fantasi lainnya dari luar. Padahal pengenalan tokoh-tokoh manusia super atau tokoh fantasi dari kubudayaan lokal dapat bermanfaat bagi anak-anak dan generasi muda daerah.

Hal ini sesuai dengan pendapat Sarumpaet (2010:1) bahwa kita semua pada dasarnya dibesarkan oleh cerita, oleh karya sastra yang member kita bahagia, kegirangan, pengalaman, dan harapan. Cerita-cerita itulah yang membentuk pemahaman dan wawasan kita. Artinya, cerita-cerita atau karya sastra lokal pada dasarnya dapat membentuk pemahaman dan wawasan kita mengenai budayabudaya lokal serta kearifan lokal yang terdapat di dalamnya. Sementara yang 
terlihat saat ini begitu banyak generasi muda yang lupa dan tidak paham mengenai identitas dan budaya lokalnya.

Di sini dapat dilihat bahwa karya sastra lokal masih banyak yang belum dikenal oleh generasi muda seperti halnya kaba. Khusus untuk kaba ada beberapa hal yang membuatnya sulit untuk menjadi bacaan anak-anak atau generasi muda. Salah satunya adalah sulitnya membaca dan memahami kaba itu sendiri. Kaba menurut bentuk penyajiannya menurut Djamaris (2002:77) adalah cerita prosa berirama berbentuk narasi (kisahan). Gaya prosa berirama ini ditandai dengan pola kalimatnya yang terdiri atas gatra-gatra dengan jumlah suku kata yang relatif tetap. Biasanya masing-masing gatra terdiri atas delapan suku kata, atau sepuluh kata. Lebih lanjut menurut Djamaris (2002:78), konsistensi jumlah suku kata itulah yang memungkinkan timbulnya irama dalam bahasa $k a b a$, seperti halnya metrum yang menimbulkan irama pada sebuah lagu.

Gaya bahasa dari kaba ini pada dasarnya masih mengikuti gaya bahasa dari pelisanan kaba itu karena kaba memang awalnya adalah sastra lisan. Meskipun saat ini telah ada kaba yang baru diterbitkan, tapi pada dasarnya hanya menerbitkan kembali cerita kaba dari cetakannya yang terdahulu. Menurut catatan penulis, hingga saat ini belum ada buku yang berisi kisah dari kaba dengan bahasa dan gaya bahasa sederhana, yang berbeda dengan gaya bahasa bakaba. Padahal, untuk mengenalkan tokoh, kisah, serta nilai-nilai yang ada dalam kaba itu dapat dilakukan dengan menampilkan cerita yang ada di dalamnya dengan menggunakan gaya bahasa sederhana yang dapat dimengerti dan dipahami banyak kalangan. Bahkan cerita kaba pun dapat dibuat dalam bentuk komik atau bacaan untuk anak yang penuh dengan ilustrasi.

Sulitnya memahami dan membaca kaba juga belum diikuti dengan munculnya bentuk audio visual dari cerita kaba. Hingga saat ini, kisah-kisah dari kaba baru ditampilkan dalam bentuk seni peran, seperti dalam randai. Akan tetapi, dialog antar tokoh dalam randai itu pun masih mengikuti gaya bahasa dalam kaba. Sehingga terkadang masih sulit memahami cerita kaba yang ada dalam randai. Sementara itu, kisah kaba yang telah difilmkan dan di angkat ke layar lebar baru satu, yaitu Sabai Nan Aluih sekitar tahun 1990-an. Karena sudah pernah diangkat ke layar lebar itu lah tokoh Sabai menjadi cukup terkenal, khususnya bagi generasi yang ada pada masa itu. Maka bercermin dari film Sabai Nan Aluih tersebut, mengenalkan kesusastraan lokal pada generasi muda juga dapat dilakukan dengan mengalihmediakan sebuah cerita menjadi film. Terutama mengingat saat ini generasi muda lebih banyak berkenalan dengan segala hal melalui media audio visual. Bahkan materi-materi pelajaran di sekolah pun telah dibuat dalam bentuk audio visual. 


\section{Penutup}

Paparan di atas memperlihatkan bahwa kesusastraan tradisional pada dasarnya memiliki tokoh-tokoh manusia super yang baik tindakan, kelakuan, serta peristiwa-peristiwa yang dialami, akan menjadi sorotan. Tokoh-tokoh itu pun dapat menjadi sumber inspirasi, pemacu semangat dan bahkan suri tauladan bagi generasi muda dalam kehidupan sehari-hari mereka ke depan. Hal ini salah satunya ada dalam kesusastraan tradisional Minangkabau, yaitu kaba.

Dalam kaba Minangkabau, melalui analisis di atas ditemukan tiga tokoh manusia super yaitu Cindua Mato, Anggun Nan Tongga, dan Rambun Pamenan. Ketiga tokoh ini memiliki kelebihan-kelebihan yang membuatnya berbeda dari manusia biasa.

Namun begitu, ketiga tokoh tersebut tidak begitu terkenal, bahkan di kalangan masyarakat Minangkabau sendiri. Khususnya di kalangan generasi muda. Salah satu penyebabnya adalah sulitnya untuk membaca dan memahami cerita dalam kaba yang hingga saat ini yang mudah diakses oleh masyarakat ada dalam bentuk bacaan dan seni pertunjukan randai. Gaya bahasa penceritaan kaba yang berbentuk buku bacaan dan seni pertunjukan randai adalah gaya prosa berirama. Dalam dialog pun begitu banyak bunga-bunga bahasa yang membuat cerita tidak mudah untuk dipahami.

Berbeda dengan tokoh-tokoh manusia super dari kesusastraan tradisional yang ada di Jawa seperti Gatot Kaca, tokoh dari kaba ini juga tidak muncul dalam bentuk-bentuk yang lebih dekat dan mudah dipahami oleh generasi saat ini. Belum ada kisah kaba yang dibuat dalam bentuk komik atau cerita bergambar untuk anak, juga diangkat menjadi sebuah film. Hingga saat ini kisah kaba yang sudah pernah diangkat ke layar lebar adalah Sabai Nan Aluih. Padahal kaba menyediakan banyak sekali materi untuk diangkat dan dialihmediakan, salah satunya menjadi film. Sementara itu, kisah yang mengangkat tokoh Gatot Kaca telah muncul dalam berbagai bentuk. Ada dalam bentuk bacaan untuk anak, film, bahkan sering diceritakan kembali dalam bentuk pertunjukan drama, komedi, dan lainlain.

Indonesia yang kaya dengan keragaman etnisnya juga kaya dengan kesusastraan tradisional yang berasal dari berbagai etnis itu. Tokoh-tokoh manusia super yang ada dalam kesusastraan tersebut adalah salah satu aset yang dapat diolah menjadi berbagai bentuk yang baru, yang tetap 
mengenalkan nilai-nilai budaya serta kearifan lokal bagi generasi muda. Bahkan juga dapat menghasilkan sesuatu yang bernilai ekonomis juga bagi masyarakat. Untuk itu, usaha untuk menggali lagi hasil kebudayaan yang ada di tengah masyarakat kita perlu dilakukan, baik berupa kajian maupun pengolahannya.

\section{Daftar Pustaka}

Bunanta, Murti. Problematika Penulisan Cerita Rakyat untuk Anak di Indonesia. Djamaris, Edwar. 2002. Pengantar Sastra Rakyat Minangkabau. Jakarta: Yayasan Obor Indonesia.

Endah, Sy.St.Rajo. 1987. Cindua Mato. Bukittinggi: Penerbit Pustaka Indonesia

Junus, Umar. 1984. Kaba dan Sistem Sosial Minangkabau; Suatu Problema Sosiologi Sastra. Jakarta: PN Balai Pustaka.

Mahkota, Ambas. 2011. Kaba Anggun Nan Tongga. Bukittinggi: Kristal Multimedia

Mangkudun, Sutan dan Ilyas Sutan Pangaduan. 2011. Kaba Rambun Pamenan. Bukittinggi: Kristal Multimedia.

Meigalia, Eka., dkk. 2011. “Dari Kaba Klasik Minangkabau Menjadi Bacaan Anak", Laporan Penelitian Dosen Muda Universitas Andalas. Padang: FS UNAND.

Sarumpaet, Riris K. 1976. Bacaan Anak; Suatu Penyelidikan Pendahuluan ke Dalam Hakekat, Sifat, dan Corak Bacaan Anak-Anak serta Minat Anak pada Bacaannya. Jakarta: Pustaka Jaya.

Obor.

2010. Pedoman Penelitian Sastra Anak. Jakarta: Yayasan

Sudjiman, Panuti. 1991. Memahami Cerita Rekaan. Jakarta : Pustaka Jaya. 